\title{
PENATAAN FISIK KAWASAN WISATA TANGGO RAJO, KOTA JAMBI SEBAGAI KAWASAN WISATA BERKONSEP WATERFRONT
}

\author{
Bondan Wira Wicaksana ${ }^{1)}$, Parino Rahadjo ${ }^{2)}$, Suryono Herlambang ${ }^{3)}$ \\ 1)Program Studi S1 PWK, Fakultas Teknik, Universitas Tarumanagara, bondanwirawicaksana@gmail.com \\ 2) Program Studi S1 PWK, Fakultas Teknik, Universitas Tarumanagara, parinor19@gmail.com \\ 3) Program Studi S1 PWK, Fakultas Teknik, Universitas Tarumanagara, s.herlambang@gmail.com
}

Masuk: 03-08-2021, revisi: 24-08-2021, diterima untuk diterbitkan: 23-10-2021

\begin{abstract}
Abstrak
Kawasan Wisata Tanggo Rajo merupakan area wisata dan ruang terbuka publik yang berada di Kecamatan Pasar Jambi, Kota Jambi. Kawasan ini memiliki luas kurang lebih 7 $\mathrm{Ha}$, daya tarik utamanya adalah menikmati suguhan makanan lokal yang dijual oleh PKL dari pingiran Sungai Batanghari dan menikmati suasana kota lama pada Kawasan Sebrang Kota Jambi serta Kawasan Menara Gentala Arasy. Melihat dari banyaknya persentase pengunjung yang cukup ramai setiap hari, peniliti melihat beberapa potensi wisata yang ada dapat dikembangkan dengan dengan sentuhan penataan kawasan wisata yang baik. Untuk itu peneliti bertujuan untuk merumuskan rencana penataan Kawasan Wisata Tanggo Rajo kedalam konsep waterfront development, melihat keberadaan kawasan ini yang berada di pinggir sungai sehingga cocok dengan konsep tersebut. Selain itu penelitian ini mengunakan pendekatan kualitatif dengan analisis deskriptif. Beberapa analisis seperti analisis kebijakan, lokasi, tapak, wisata, benchmark, dan kebutuhan ruang. Dan penelitian ini akan ditunjukan kepada Pemerintah setempat sebagai sebuah rekomenasi rencana penataan kawasan wisata yang ideal.
\end{abstract}

Kata kunci: Kawasan Tanggo Rajo; Kawasan Tepi Air; Penataan Kawasan

\begin{abstract}
Tanggo Rajo Tourism Area is a tourist area and public open space located in Pasar Jambi District, Jambi City. This area has an area of approximately 7 hectares, the main attraction is enjoying local food treats sold by street vendors from the outskirts of the Batanghari River and enjoying the atmosphere of the old city in the Sebrang area of Jambi City and the Gentala Throne Tower area. Seeing from the large percentage of visitors who are quite busy every day, the researchers see that some of the existing tourism potential can be developed with a touch of good tourist area arrangement. For this reason, the researcher aims to formulate a plan for structuring the Tanggo Rajo Tourism Area into the concept of waterfront development, seeing the existence of this area which is on the edge of the river so that it fits the concept. In addition, this study uses a qualitative approach with descriptive analysis. Some analyzes such as policy analysis, location, site, tourism, benchmarks, and space requirements. And this research will be shown to the local government as a recommendation for an ideal tourist area arrangement plan.
\end{abstract}

Keywords: Regional Planning; Tanggo Rajo Area; Waterfront Development

\section{PENDAHULUAN \\ Latar Belakang}

Dalam beberapa tahun terakhir sungai semakin menarik dalam sudut pandang perencanaan kota, namun sungai-sungai di perkotaan telah mengalami perkembangan yang dimana sungai ini terlalu lama diabaikan, jika dilakukan penatatan sungai yang baik dapat menjadi sebuah identitas kota itu sendiri. Kota Jambi dalam RTRW Kota Jambi Tahun 2013-2033 mengarahkan perencanaan kotanya kearah sungai, dimana kota ini dibelah oleh Sungai Batanghari, namun penerapannya belum optimal 
sampai saat ini. Sungai ini merupakan sungai terpanjang di Pulau Sumatra memiliki panjang sampai dengan $800 \mathrm{~km}$. DAS Batang Hari merupakan DAS terbesar kedua di Indonesia, mencakup catchment area \pm 4.9 Juta $\mathrm{Ha}$. Kota Jambi telah mengalami banyak perkembangan yang cukup pesat, hal ini dapat dilihat pada kondisi eksisting saat ini. BPS Kota Jambi Tahun 2020 menyebutkan dimana sektor perdagangan dan jasa merupakan sektor utama dari Kota Jambi. Sedangkan dari sektor pariwisata belum terlalu besar dampak dan pengaruhnya terhadap perkembangan Kota Jambi, hal ini sangat disayangkan karena Kota Jambi sebagai pintu masuk utama ke Provinsi Jambi, namun pengelolaan wisata kota pada Kota Jambi belum terkelola dengan baik. Kurangnya perencanaan dan perawatan pada destinasi wisata kota yang ada membuat kurangnya minat wisatawan untuk berkunjung ke destinasi wisata kota yang ada di Kota Jambi.

Kawasan Wisata Tanggo Rajo merupakan salah satu Wisata Kota yang ada di Kota jambi. Kawasan ini merupakan pusat pedagang kaki lima (PKL) serta menjadi tempat transit perahu untuk menuju ke Sebrang Kota Jambi. Kawasan Wisata Tanggo Rajo yang berlokasi yang di Jalan Sultan Thaha, Kelurahan Pasar Jambi, Kecamatan Pasar Jambi, Kota Jambi. Namun sebagian wilayah kawasan wisata ini juga berada di Kelurahan Kasang, Kecamatan Jambi Timur. Kawasan Tanggo Rajo tercantum pada Rencana Tata Ruang Wilayah (RTRW) Kota Jambi Tahun 2013-2033 sebagai kawasan wisata, pada Pasal 60 sebagai rencana pengembangan kawasan wisata dalam revitalisasi dan rehabilitasi Kawasan Wisata Tanggo Rajo dan Pasal 62 sebagai rencana kawasan peruntukan sektor informal dalam penataan PKL di Kawasan Wisata Tanggo Rajo.

Kawasan Tanggo Rajo sebenarnya diperuntukan sebagai sarana wisata dari Jembatan Pedestrian dan Menara Gentala Arasy. Tahun 2015 Pemerintah melakukan revitalisasi pada Kawasan ini sebagai penunjang Jembatan Pedestrian dan Menara Gentala Arasy, namun tidak adanya perawatan yang lebih lanjut membuat kondisi eksisting pada kawasan ini sangat tidak tertata. Pada sisi barat Kawasan ini terdapat bangunan campuran WTC Batanghari yang menyalahi aturan sempadan sungai, sebagaimana dalam Permen PUPR No.28 Tahun 2015 menyebutkan jarak paling sedikit berjarak $15 \mathrm{~m}$ dari tepi kiri dan kanan palung sungai sepanjang alur sungai, dalam hal kedalaman sungai lebih dari 3 $\mathrm{m}$ sampai dengan $20 \mathrm{~m}$, dalam hal ini Sungai Batanghari sendiri memiliki kedalam sampai dengan 10 $\mathrm{m}$. Bangunan campuran ini berdiri pada bekas lahan pelabuhan boom batu serta mengabil lahan dari Sempandan Sungai Batanghari.

Oleh karena itu, penulis ingin melakukan penataan fisik pada Kawasan Wisata Tanggo Rajo dan bangunan campuran WTC Batanghari yang berfokus pada mengintergrasikan dari kedua zona ini menjadi satu Kawasan sebagai kawasan wisata kota terpadu yang berbasis pada perencanaan dan penataan berkonsep Waterfront development.

\section{Rumusan Permasalahan}

Kota Jambi memiliki potensi sungai besar yaitu Sungai Batanghari yang menjadi pusat kegiatan utama Kota Jambi. Pada Kawasan tepi Sungai Batanghari terdapat salah satu kawasan ruang terbuka publik yaitu Kawasan Wisata Tanggo Rajo. Pada Tahun 2015 telah dilakukannya revitalisasi pada kawasan wisata ini, namun pada tahun selanjutnya tidak adanya perawatan yang lebih lanjut dari Pemerintah sehingga kawasan ini tidak tertata dan tidak optimalnya Kawasan Wisata Tanggo Rajo sebagai kawasan wisata yang sebagaimana telah tercantum pada RTRWKota Jambi Tahun 2013-2033. Dan pada bangunan campuran WTC Batanghari yang telah melangar sempadan sungai yang telah ditetapkan pada Peraturan Kementrian PUPR Nomor 28 Tahun 2015 pasal 5 sehingga hilangnya fungsi alami sempadan sungai yang berada pada kawasan bangunan campuran WTC Batanghari.

\section{Tujuan}

Tujuan dari penelitian ini adalah:

a. Mengidentifikasi karakteristik fisik Kawasan Wisata Tanggo Rajo. 
b. Mengusulkan solusi dari permasalahan-permasalahan yang terdapat pada Kawasan Wisata Tanggo Rajo.

c. Membuat usulan penataan dan merancanakan Kawasan Tanggo Rajo sebagai Kawasan wisata kota berkonsep waterfront development yang sebagaimana tercantum pada Rencana Tata Ruang Wilayah (RTRW) Kota Jambi Tahun 2013-2033.

\section{KAJIAN LITERATUR}

\section{Waterfront Development}

Waterfront Development adalah suatu usaha penataan dan pengembangan kawasan perkotaan yang skala kegiatan dan fungsinya yang sangat beragam dengan intensitas tinggi sebagai kegiatan perkotaan baik untuk fungsi perumahan, pelabuhan dan dermaga, komersial, industry, dan Kawasan wisata. Pengertian waterfront dalam Bahasa Indonesia secara harfiah adalah daerah yang berada pada tepian laut, bagian kota yang berbatasan dengan air, dan daerah pelabuhan (Enchols, 2003).

\section{Sungai dan Sempadan Sungai}

Sungai adalah air yang berada pada permukaan daratan, yang akan mengalir melalui saluran menuju tempat yang lebih rendah (Wardani, 2018). Menurut Peraturan Mentri PUPR No. 28/PRT/M/Tahun 2015 menjelaskan Garis Semapadan Sungai (GSS) adalah garis maya di kiri dan kanan palung sungai yang ditetapkan sebagai batas perlindungan dari sungai. Penetapan Garis Sempadan Sungai (GSS) dimaksudkan sebagai upaya agar kegiatan pada perlindungan, pengunaan dan pengendalian atas sumber daya yang ada pada sungai dapat dilaksanakan sesuai dengan tujuannya. Penetapan Garis Sempadan Sungai.

\section{Penataan Ruang}

Menurut Undang-Undang Republik Indonesia Nomor 26 Tahun 2007 Pasal 1 ayat 2. Penataan Ruang adalah wujud struktur ruang dan pola ruang. Dalam pasal 1 sub 10 Undang-Undang Nomor 26 Tahun 2007 tentang penataan ruang dinyatakan bahwa Kawasan suatu perkotaan adalah Kawasan yang mempunyai kegiatan utama yang bukan dari sektor pertanian dengan susunan fungsi Kawasan sebagai tempat permukiman kota, pemusatan dan distribusi pelayanan dan jasa pemerintah, pelayanan sosial dan kegiatan ekonomi.

\section{Fasilitas Wisata}

Menurut Peraturan Mentri Pariwisata Republik Indonesia No.03 Tahun 2018, terdapat beberapa standar fasilitas yang dibutuhkan pada suatu kawasan wisata. Berikut merupakan standar fasilitas yang dibutuhkan pada suatu kawasan wisata menurut Permen Parwisata No.03 Tahun 2018, sebagai berikut:
1. Pusat Informasi/TIC
8. Pusat jajanan kuliner
2. Ruang Ganti dan Toilet
9. Tempat ibadah
3. Gazebo
4. Lampu taman
10. Menara pandang (View deck)
5. Pagar pembatas
11. Gapura indentitas
6. Panggung kesenian (Amphitheater)
12. Jalur pejalan kaki (Pedestrian)
13. Rambu-rambu petunjuk arah

7. Kios cinderamata

\section{METODE}

\section{Lokasi Penelitian}

Lokasi objek penelitian yang penulis teliti adalah Kawasan Wisata Tanggo Rajo yang berlokasi di Jalan Sultan Thaha, Kelurahan Pasar, Kecamatan Pasar Jambi, Kota Jambi. 

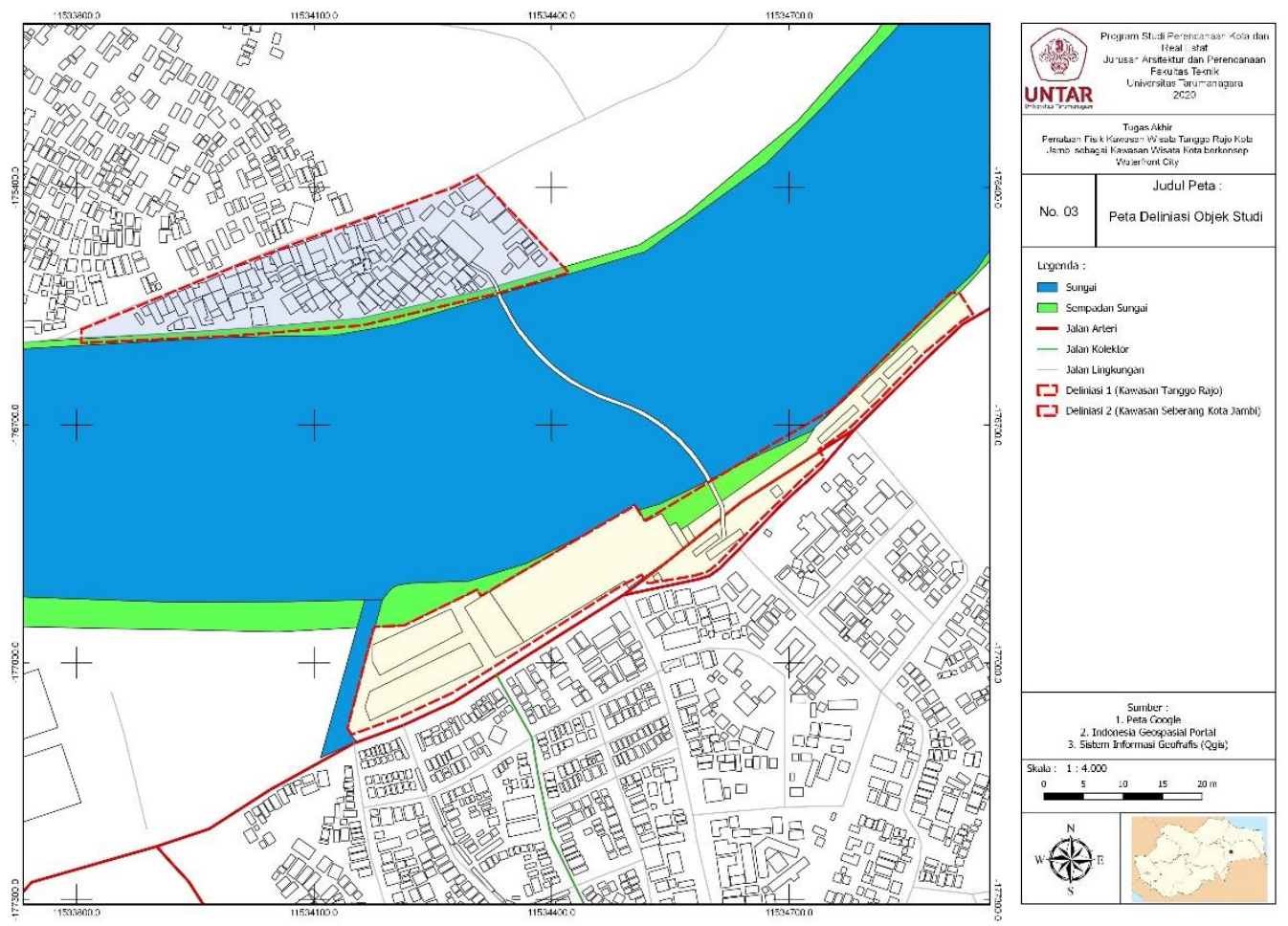

Gambar 1. Lokasi Penelitian

Sumber: Olahan Pribadi,2021

\section{Metode Pengumpulan Data}

Dalam penenlitian ini terdapat tiga metode pengumpulan data, antara lain sebagai berikut.

a. Data Primer

Pengumpulan data sebagai berikut.

1. Observasi

2. Melakukan Wawancara

3. Dokumentasi

Observasi dilakukan untuk mengetahui keadaan fisik lokasi penelitian, sedangkan wawancara dengan pemangku kepentingan untuk mendapatkandata mengenai pembangunan yang akan dan sudah ada berikut masalah pada lokasi penlitiaan, sedangakan dokumen mencari data perihal kebijakan pengembangan dan kebjakan yang berlaku pada lokasi penelitain.

\section{Metode Analisis}

Analisis Deskriptif

Analisis Deskriptif merupakan suatu analisis yang dilakukan untuk memperoleh suatu gambaran tentang suatu hal dengan penyajian hasil peringkasan atau penelitian tersebut. Tujuannya adalah agar data yang akan disajikan dalam bentuk yang lebih mudah dan lebih cepat dimegerti dan dipahami.

\section{DISKUSI DAN HASIL}

Pada bagian diskusi dan hasil ini membahas bagian garis besar yang dilakukan dalam penelitian ini, yakni Rencana Penataan Kawasan Tanggo Rajo dengan Konsep Waterfront Development. 


\section{Zonasi Lahan Perencanaan}
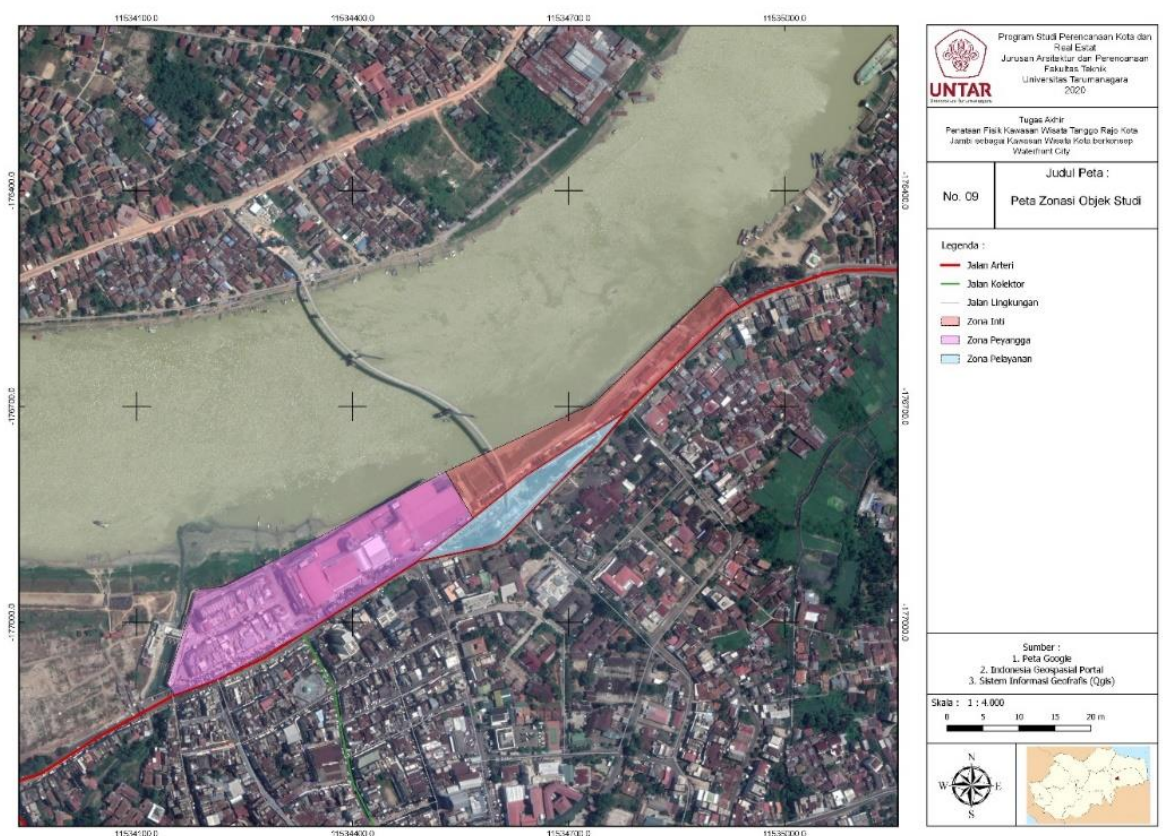

Gambar 2. Peta Zonasi Lahan Perencanaan Sumber: Olahan Pribadi, 2021

Dari pemengalan ruang zonasi yang ada pada kawasan perencanaan, penulis dapat menetukan batasan penelitian dalam melakukan rencana penataan kawasan wisata Tanggo Rajo dengan mengfokuskan deliniasi perencanaan pada deliniasi 1 dengan luas 5,55 Ha. Dimana pada zona inti memiliki luas $1,5 \mathrm{Ha}$, zona peyangga memiliki luas 3,5 dan zona pelayanan dengan luas 0,55.

\section{Kategorisasi Lahan Perencanaan dan Kepemilikan Lahan}
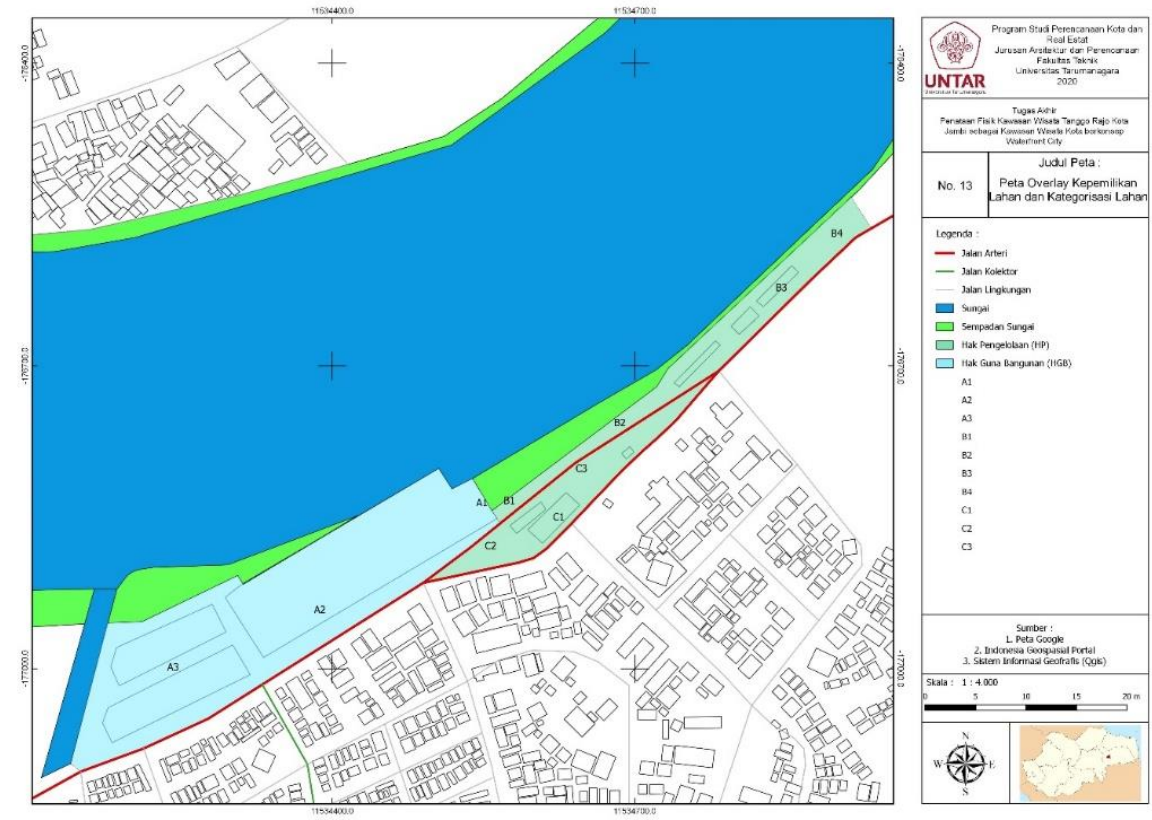

Gambar 3. Peta Overlay Kategorisasi Lahan dan Kepemilikan Lahan Sumber: Olahan Pribadi, 2021

Pada gambar ditas telah dilakukan kategorisasi lahan yang membagi lahan perencanaan menjadi 3 zona yakni zona lahan A, zona lahan B dan zona lahan C. pada zona lahan A terdapat lahan terdapat 
sub zona lahan $\mathrm{A} 1, \mathrm{~A} 2$ dan $\mathrm{A} 3 y$ ang merupakan lahan dengan peruntukan komersial dan campuran serta mempunyai jenis kepemilikan lahan yaitu Hak Guna Bangunan (HGB). Pada zona lahan B terdapat sub zona B1, B2, B3 dan B4 yang peruntukan lahannya untuk kawasan wisata dengan jenis kepemilikan lahanya yaitu Hak Pengelolaan (HP). Dan untuk zona lahan C terdapat lahan dengan sub zona lahan C1, C2dan C3 yang juga merupakan kawasan wisata sebabagai peruntukannya serta memiliki jenis kepemilikan lahan dengan Hak Pengelolaan (HP).

Tabel 1. Data Overlay Kepemilikan Lahan dan Kategorisasi Lahan

\begin{tabular}{|c|c|c|c|c|c|}
\hline $\begin{array}{l}\text { Zona } \\
\text { Lahan }\end{array}$ & $\begin{array}{c}\text { Pembagian } \\
\text { Lahan }\end{array}$ & $\begin{array}{l}\text { Luas } \\
\text { (Ha) }\end{array}$ & $\begin{array}{l}\text { Kondisi } \\
\text { Eksisting } \\
\text { Lahan }\end{array}$ & $\begin{array}{c}\text { Jenis } \\
\text { Kepemilikan } \\
\text { Lahan }\end{array}$ & Kesimpulan \\
\hline \multirow[b]{3}{*}{ A } & A1 & 0,10 & Hotel Wiltop & \multirow[b]{3}{*}{$\begin{array}{l}\text { Hak Guna } \\
\text { Bangunan }\end{array}$} & \multirow{3}{*}{$\begin{array}{l}\text { - Hak Guna Bangunan } \\
\text { memiliki jangka waktu } \\
\text { yang pemaamfaatan yaitu } \\
\text { selama } 30 \text { tahun. } \\
\text { - Tanah dimiliki oleh } \\
\text { Pemerintah Provinsi Jambi } \\
\text { sehingga tidak perlu } \\
\text { melakukan ganti rugi }\end{array}$} \\
\hline & $\mathrm{A} 2$ & 1,97 & $\begin{array}{l}\text { Mall WTC } \\
\text { Batanghari }\end{array}$ & & \\
\hline & $\mathrm{A} 3$ & 1,48 & $\begin{array}{l}\text { Ruko WTC } \\
\text { Batanghari }\end{array}$ & & \\
\hline \multirow{4}{*}{ B } & B1 & 0,09 & $\begin{array}{l}\text { Dermaga } \\
\text { Wisata }\end{array}$ & \multirow{7}{*}{$\begin{array}{c}\text { Hak } \\
\text { Pengelolaan }\end{array}$} & \multirow{7}{*}{$\begin{array}{l}\text { - Hak pengelolaan } \\
\text { merupakan hak yand } \\
\text { dimiliki oleh instansi } \\
\text { pemerintahan } \\
\text { - Lahan dimiliki oleh } \\
\text { Pemerintah Provinsi Jambi } \\
\text { - Tidak perlu adanya ganti } \\
\text { rugi }\end{array}$} \\
\hline & B2 & 0.38 & $\begin{array}{l}\text { Ruang } \\
\text { Terbuka } \\
\text { Publik }\end{array}$ & & \\
\hline & B3 & 0,37 & Kawasan PKL & & \\
\hline & B4 & 0,25 & Lahan Kosong & & \\
\hline \multirow{3}{*}{ C } & $\mathrm{C} 1$ & 0,10 & $\begin{array}{l}\text { Akses Masuk } \\
\text { Jembatan }\end{array}$ & & \\
\hline & $\mathrm{C} 2$ & 0,11 & Taman & & \\
\hline & C3 & 0,19 & Area Parkir & & \\
\hline & nlah & 5,04 & & & \\
\hline
\end{tabular}

Sumber: Olahan Pribadi, 2021

\section{Rencana Penataan Pada Kawasan}

Pada bagian ini berisi menganai rincian penataan yang didapatkan setelah melakukan seluruh analisi, terbagi menjadi rincian penataan lahan dan rincian penataan jalan pada Kawasan Wisata Tanggo Rajo.

Tabel 2. Rencana Penataan Jalan

\begin{tabular}{|c|c|c|}
\hline Jalan & Rencana & Dasaran \\
\hline Jalan Sultan Thaha & $\begin{array}{ll}\text { - } & \text { Rencana Jaringan Pejalan } \\
\text { - } & \text { Kaki } \\
\text { - } & \text { Penyediaan Signane } \\
\text { - } & \text { Pelican Cross }\end{array}$ & $\begin{array}{c}\text { Peraturan Mnetri PUPR } \\
\text { No.03/PRT/M/Tahun } 2014\end{array}$ \\
\hline
\end{tabular}

Sumber: Olahan Pribadi, 2021 
Tabel 3. Rencana Penataan Lahan

\begin{tabular}{|c|c|c|c|c|}
\hline $\begin{array}{l}\text { Zona } \\
\text { Lahan }\end{array}$ & $\begin{array}{c}\text { Pembagia } \\
\text { n Lahan }\end{array}$ & Rencana & Dasaran & Rincian \\
\hline \multirow[t]{3}{*}{ A } & $\mathrm{A} 1$ & $\begin{array}{l}\text { Mall WTC } \\
\text { Batanghari. }\end{array}$ & & $\begin{array}{l}\text { Bangunan Mall WTC Batanghari } \\
\text { dipertahankan namun pada area } \\
\text { yang mendapati pada sempadan } \\
\text { sungai akan dibongkar untuk } \\
\text { membangun jalur promenade. }\end{array}$ \\
\hline & $\mathrm{A} 2$ & $\begin{array}{l}\text { Hotel Wiltop } \\
\text { Jambi }\end{array}$ & & $\begin{array}{l}\text { Bangunan } \text { Hotel Wiltop } \\
\text { dipertahankan namun akan } \\
\text { dilakukan revitalisasi bangunan } \\
\text { ini, dan pada area yang } \\
\text { mendapati pada sempadan } \\
\text { sungai akan dibongkar untuk } \\
\text { membangun jalur promenade. }\end{array}$ \\
\hline & A3 & $\begin{array}{l}\text { Kawasan Ruko } \\
\text { WTC } \\
\text { Batanghari }\end{array}$ & $\begin{array}{l}\text { - } \text { Analisis } \\
\text { Permen PUPR } \\
\text { No.26 Tahun } \\
2015\end{array}$ & $\begin{array}{l}\text { Bangunan Ruko akan tetap } \\
\text { dipertahankan dan dilakukan } \\
\text { revitalisasi serta penambahan } \\
\text { fasilitas, seperti: } \\
\text { - Koridor pejalan kaki } \\
\text { - Taman } \\
\text { - Kolam air mancur } \\
\text { - Rak sepeda } \\
\text { - Tempat sampah } \\
\text { - Signane } \\
\text { - Lampu taman } \\
\text { - Jalur promande }\end{array}$ \\
\hline \multirow[t]{2}{*}{ B } & B1 & $\begin{array}{l}\text { Kawasan } \\
\text { Ruang Terbuka } \\
\text { Publik }\end{array}$ & $\begin{array}{l}\text { - Gagasan Penulis } \\
\text { - benchmark }\end{array}$ & $\begin{array}{l}\text { Mempertahankan area ruang } \\
\text { terbuka public dengan } \\
\text { penambahan fasilitas, seperti: } \\
\text { - Taman } \\
\text { - Children playground } \\
\text { - Jalur promenade } \\
\text { - Lampu taman } \\
\text { - Gazebo } \\
\text { - Rak sepeda } \\
\text { - Signane } \\
\text { - Tempat sampah } \\
\text { - Bangku taman } \\
\text { - Dermaga perahu }\end{array}$ \\
\hline & B2 & Kawasan PKL & & $\begin{array}{l}\text { Pada area PKL akan dilakukan } \\
\text { revitalasi dengan penamaban } \\
\text { jalur pejalan kaki }\end{array}$ \\
\hline C & C1 & $\begin{array}{l}\text { Merokemenda } \\
\text { sikan reviltasi } \\
\text { kawasan } \\
\text { parkir dan } \\
\text { taman }\end{array}$ & & $\begin{array}{l}\text { - Membuat area parkir } \\
\text { untuk motor,mobil, dan } \\
\text { bus. } \\
\text { - } \begin{array}{l}\text { Revitalasisasi kawasan } \\
\text { taman }\end{array}\end{array}$ \\
\hline
\end{tabular}

Sumber: Olahan Pribadi, 2021 


\section{Rencana Jaringan Jalan}

Pada rencana jaringan jalan berdasarkan analisis yang dilakukan, arahan penataannya berupa pelebaran pedestrian sesuai dengan standar minimal dan ramah difabel sesuai dengan Permen PUPR No.02 Tahun 2018. Berikut gambar rencana potongan jalan pada kawasan objek studi.

Jalan Sultan Thaha

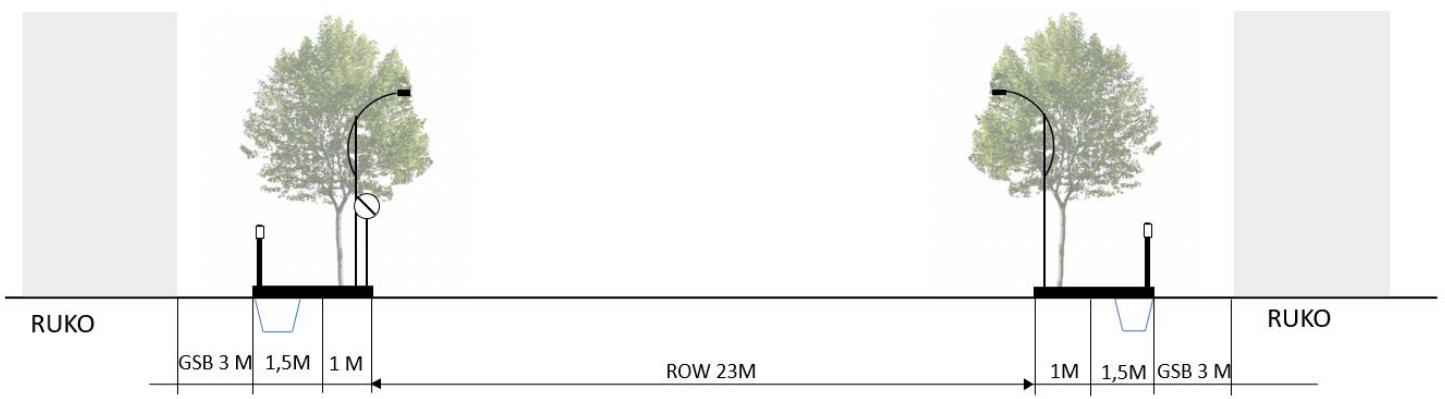

Gambar 4. Rencana Jalan Pada Kawasan Objek Studi Sumber: Olahan Pribadi, 2021

\section{Rencana Siteplan Pada Kawasan}

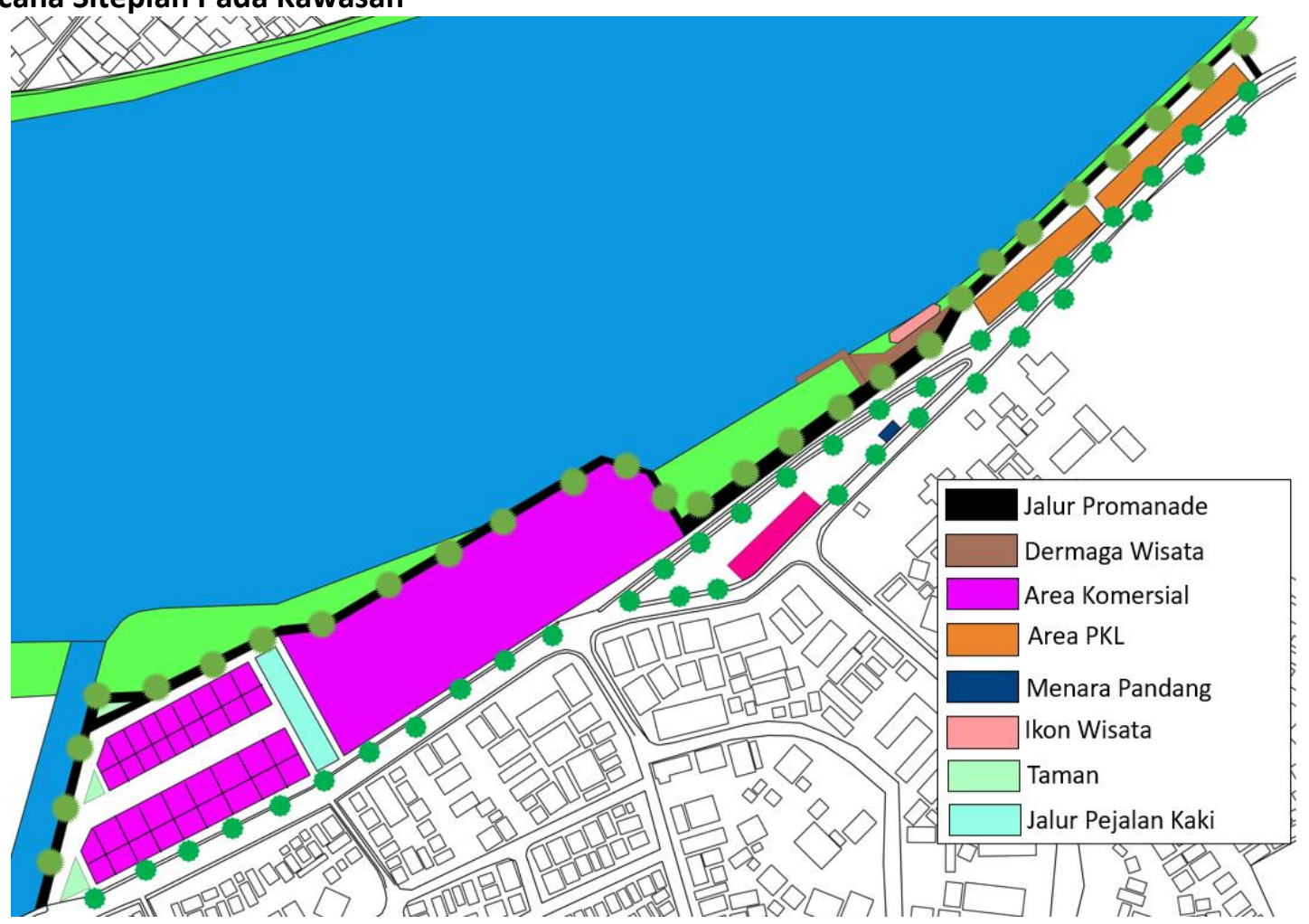

Gambar 5. Peta Usulan Siteplan Pada Kawasan

Sumber: Olahan Pribadi, 2021

Pada gambar diatas merupakan peta usulan rencana siteplan pada kawasan, terdapat beberapa rencana mulai dari rencana Rencana Dermaga Wisata, Rencana Ruang Terbuka Publik, Rencana Jalur Promanade. Berikut beberapa gambar ilustrasi kawasan daro rencana diatas. 


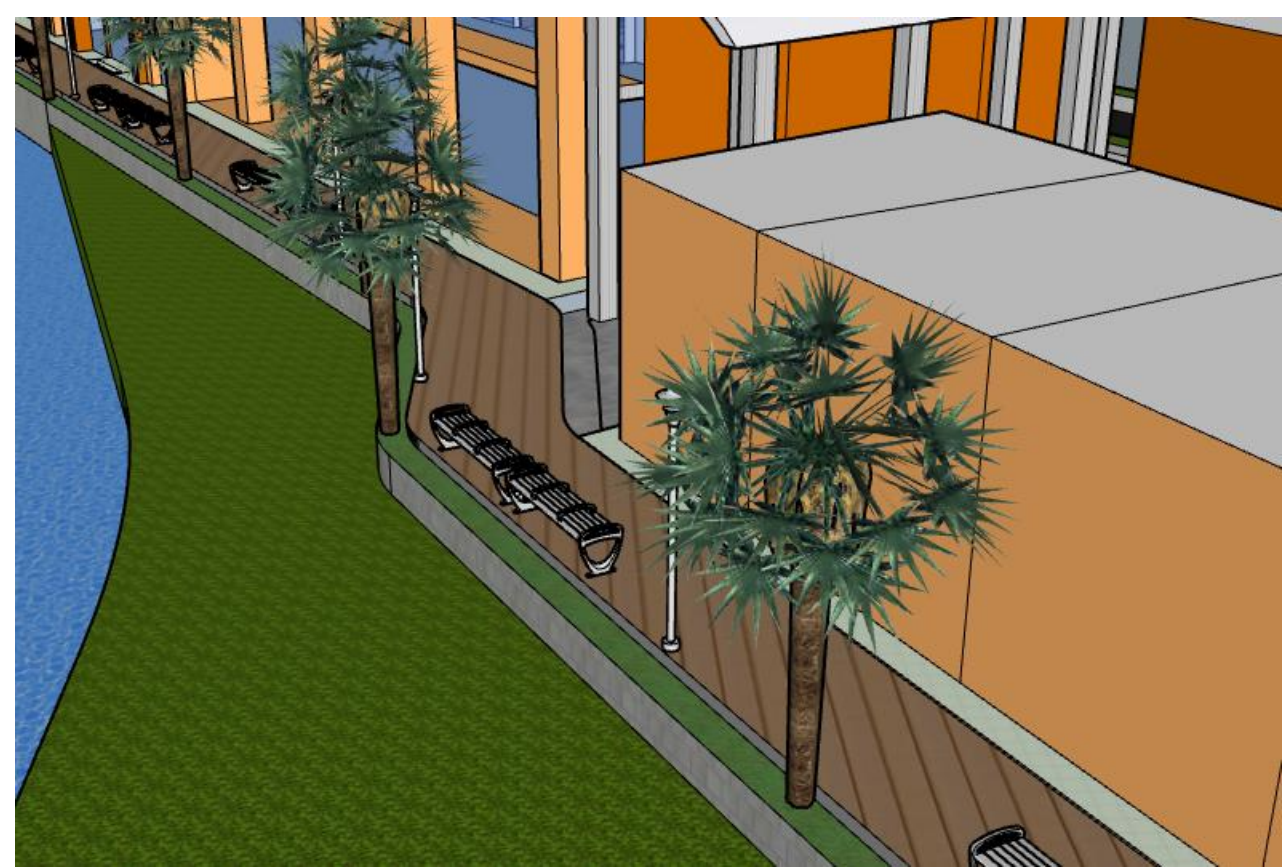

Gambar 6. Ilustrasi Rencana Jalur Promanade Sumber: Olahan Pribadi, 2021

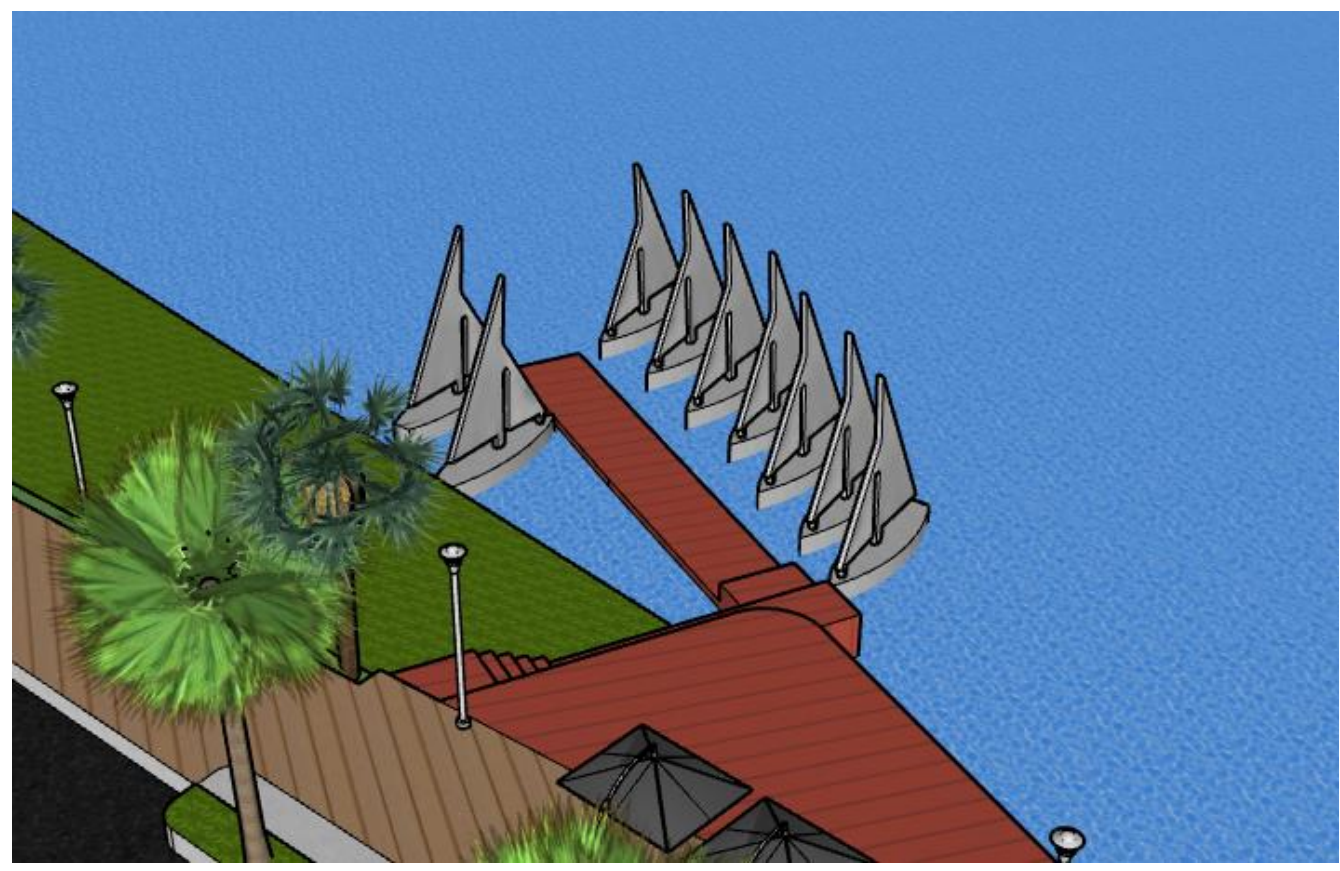

Gambar 7. Ilustrasi Rencana Dermaga Wisata Sumber: Olahan Pribadi, 2021 


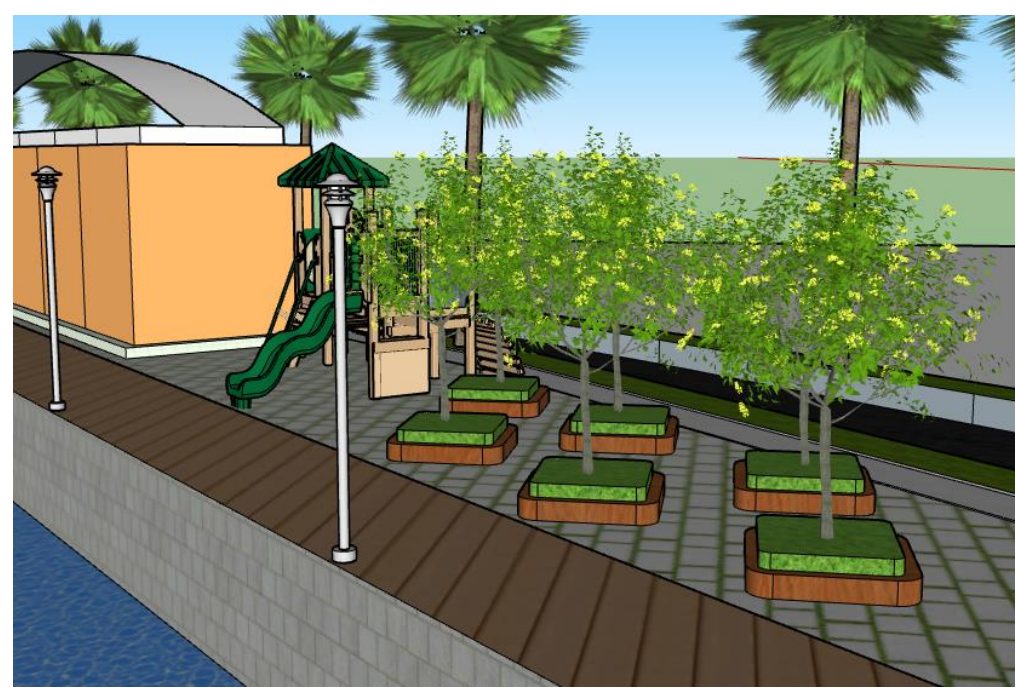

Gambar 8. Ilustrasi Rencana Ruang Terbuka Publik Sumber: Olahan Pribadi, 2021

\section{KESIMPULAN DAN SARAN}

\section{Kesimpulan}

Berdasarkan hasil keselurahan penelitian ini mengenai rencana pentaan kawasan wisata Tanggo Rajo, maka didapatkan kesimpulan seagai berikut.

a. Penentuan konsep waterfront dilihat dari kondisi dan aktifitas eksisting wisata tersebut yaitu rekreasi dan edukasi.

b. Kegaiatan wisata belum terkelola dengan baik, masih banyak pelayanan yang belum maksimal.

c. Para pengunjung dan masyarakat sekitar cukup ramai dan mendukung setiap kegiatan yang ada pada kawasan ini.

\section{Saran}

Adapun Saran yang dibuat oleh penulis untuk instasi terkait mengenai Rencana Penataan Kawasan Wisata Tanggo Rajo, sebagai berikut:

a. Untuk instansi terkait didalam Kawasan Wisata Tanggo Rajo, ciptakanlah interaksi agar wisata pada lahan perencanaan dapat saling terintegrasi dengan baik.

b. Rekomendasi rencana penataan kawasan ini ditampilkan untuk menarik para investor untuk datang, dengan menciptakan atraksi yang menarik.

c. Penambahan angkutan umum dapat mempermudah akses menuju kawasan wisata Tanggo Rajo

\section{REFERENSI}

Binus University (2014): Benchmarking, Repository Binus University, Jakarta.

BPS Kota Jambi (2019): Kota Jambi dalam angka 2019, Kota Jambi.

Indonesia, K. r. (2007): Undang-Undang Nomor 26 Tahun 2007 tentang Pentaan Ruang, Jakarta.

Indonesia, K. r. (2009): Undang-Undang Nomor 10 Tahun 2009 tentang Kepariwisataan, Jakarta.

Jambi, P. K. (2013) Rencana Tata Ruang Wilayah Kota Jambi Tahun 2013-2033, Kota Jambi.

Jambi, P. K. (2013) Rencana Pembangunan Jangka Menengah Daerah Kota Jambi Tahun 2013-2018, Kota Jambi.

Kotaku.pu.go.id (2016): Memahami pentingnya Tata Ruang Kota.

Law, C. M. (1996): Tourism in Major Cities, International Thomson Business Press, London.

Martin P. (2012): River-Space-Design Planning Strategies, Methods and Projects for Urban Rivers, Birkahauser.

Page, S. (1995): Urban Toursim, Routlegde, London.

PUPR, K. (2015): PM RI Nomor 28/PRT/M/2015 tentang garis sempadan sungai dan danau, Jakarta.

Torre, L, Azeo (1989): Waterfront Development, Van Nostrand Reinhold, New York. 